\title{
Heat transfer behaviour of a dilute impinging air-water mist jet at low wall temperatures
}

\author{
C. Quinn ${ }^{\mathrm{a}, 1}$, D. B. Murray ${ }^{\mathrm{b}}$, T. Persoons ${ }^{\mathrm{b}}$ \\ ${ }^{a}$ UCD School of Mechanical and Materials Engineering, University College Dublin, Belfield, \\ Dublin 4, Ireland \\ ${ }^{b}$ Dept. of Mechanical and Manufacturing Engineering, Trinity College Dublin, The \\ University of Dublin, Dublin 2, Ireland
}

\begin{abstract}
This paper presents experimental work on the heat transfer characteristics of a dilute impinging air-water mist jet. Time-averaged heat transfer measurements are reported, as well as simultaneously obtained high-speed shadowgraph imaging flow visualisation and heat transfer measurements; images of the mist jet impingement and the liquid film that forms on the impingement surface are also included. It is determined that the surface liquid morphology varies with mist loading fraction, and that the heat transfer behaviour of the mist jet reflects these changes. Intermittent thermal disturbance caused by the impingement of the mist jet droplets is proposed as the dominant heat transfer mechanism when the mist loading fraction is very low; as the mist loading fraction increases, evaporation from the surface liquid film and convective cooling due to the film flow become more significant.
\end{abstract}

Keywords: impinging mist jet; low wall temperatures; heat transfer; liquid film behaviour; droplet dynamics; shadowgraph imaging

\section{Introduction}

The use of single-phase jets for surface cooling is a well established practice; they have been used in numerous applications where high heat transfer

\footnotetext{
${ }^{1}$ Corresponding author; ciquinn@tcd.ie
} 


\begin{tabular}{|llll|}
\hline \multicolumn{2}{l}{ Nomenclature } & & \\
$D$ & Droplet diameter & $q^{\prime \prime}$ & Heat flux \\
$D_{1,0}$ & Arithmetic mean droplet diameter & $q_{n o r m}^{\prime \prime}$ & Normalised mist jet heat flux \\
$D_{3,2}$ & Sauter mean droplet diameter & $R$ & Hot film sensor resistance \\
$D_{h}$ & Annular air jet hydraulic diameter & $r / D$ & Non-dimensional radial displacement \\
$D_{i}$ & Annular air jet inner diameter & Re & Reynolds number \\
$D_{o}$ & Annular air jet outer diameter & $t$ & Time \\
$D_{w}$ & Water jet inner diameter & $T_{j}$ & Jet temperature \\
$E$ & Hot film sensor voltage & $T_{s}$ & Surface temperature \\
$f$ & Mist loading fraction & $U$ & Jet velocity \\
$h$ & Heat transfer coefficient & $U_{h}$ & Heat transfer coefficient measurement uncertainty \\
$H / D$ & Non-dimensional nozzle-to-plate spacing & $U_{m i s t}$ & Uncertainties associated with air and water flow rates \\
$\Delta h$ & Total uncertainty in heat transfer coefficient & $V$ & Droplet velocity magnitude \\
$\dot{m}_{a}$ & Air mass flow rate & $y / D$ & Non-dimensional axial displacement above surface \\
$\dot{m}_{w}$ & Water mass flow rate & $\nu$ & Kinematic viscosity \\
$N_{d}$ & Number of droplets & & \\
\hline
\end{tabular}

levels are required, for example, in grinding [1] or electronic circuitry [2]. The

5 effects on heat transfer of jet Reynolds number, nozzle-to-plate spacing, angle of impingement and a number of other parameters have been reported on extensively [3, 4].

An improvement in jet impingement heat transfer can be obtained by using a fluid other than air, such as water, which has been shown to offer superior heat transfer characteristics [5]. However, practical issues arise, such as the removal of large amounts of water, pumping pressure requirements, storage issues and the environmental cost of potentially inefficient use of water. With these issues in mind, a potential compromise lies in the entrainment of liquid droplets within a flow of air.

A flow of droplets impinging on a surface can be categorised as either a mist jet or a spray; these are differentiated by their methods of generation. A spray is formed by forcing liquid through a small nozzle, whereas the droplets in a mist jet are produced from a liquid jet via shear driven atomisation caused by a coflowing annular air jet as momentum is transferred from the air jet to the liquid 20 jet [6, 7, 8. Thus, mist jets are inherently complex two-phase flows, and both the nature of the flow structure and the dominant heat transfer mechanisms are not fully understood. 
While a substantial body of work exists for single-phase jet impingement cooling, mist jets and sprays have not received the same levels of interest. The vast majority of work on impinging spray heat transfer has examined surface temperatures above the spray liquid saturation temperature 9]. However, spray cooling has been identified as a potential means of dissipating high heat fluxes at surface temperatures below the liquid saturation temperature, for example, in computer electronics [10, 11, 12, and the heat transfer mechanisms and parameters such as liquid flow rate, nozzle-to-plate spacing and droplet properties have been investigated [13, 14, 15. Both experimental and numerical studies have also been performed for the case of an impinging flow of water droplets entrained in steam [16, 17. Pakhomov and Terekhov [18 produced a study simulating the flow and heat transfer of a two-phase impinging jet; the authors found good agreement with the experimental data of Li et al. 16]. Wang and Dhanasekaran [19] modelled the cooling of turbine blades with impinging mist/steam jets and showed the enhancement available with the addition of mist droplets to steam jets, although the authors also showed the difficulty of numerically examining the entire flow field with a single model. The topic of non-boiling mist jet heat transfer has been the focus of even fewer studies than spray cooling. Yet it is an important topic in its own right; the addition of the air jet differentiates it from the spray and adds another dimension to the already complex heat transfer behaviour. This provides the motivation for the present heat transfer study of an air-water mist jet impinging on a surface at relatively low wall temperatures. Specifically the case of a dilute mist jet is considered.

\subsection{Mist jet heat transfer}

\subsubsection{Heat transfer mechanisms}

The heat transfer mechanisms for the mist jet have been described by Chang and $\mathrm{Su}$ [20] or Graham and Ramadhyani [21] as consisting of the following components: evaporative cooling at the liquid film-air interface; convection to the "laminar-like" [20] continuous flowing surface liquid film; disturbance to the thermal boundary layer and mixing within the film caused by droplet impacts; 
and a forced convection component due to the air jet. These mechanisms are similar to those reported for mist/steam flows, with Li et al. [17] stressing the importance of direct conduction to droplets on the impingement surface on mist/steam jet heat transfer. In addition to these mechanisms, Garbero et al. 22] reported in a numerical spray deposition study that droplets in a gas flow in the wall jet region act as vortex generators, causing gas circulation near the impingement surface, which also contribute to heat transfer enhancement.

${ }_{60}$ It is probable that the total heat transfer is due to some combination or tradeoff between these components; for example, an increase in liquid flow rate may result in an increase in the heat transfer component associated with the flow of the liquid film on the surface as greater momentum is supplied for the film flow. Conversely, it may also result in a thicker film which leads to a larger conductive

65 resistance, thereby reducing evaporation from the film and the forced convection component associated with the air jet.

\subsubsection{Effect of mist loading fraction}

As the mist jet is a two-phase two-component flow an important parameter is the ratio of the liquid to air mass flow rates, commonly referred to as the mist loading fraction, $f[20,23,24]$ :

$$
f=\frac{\dot{m}_{w}}{\dot{m}_{a}}
$$

The influence of mist loading fraction on mist jet heat transfer is not straightforward, with a general paucity of available data. Chang and $\mathrm{Su}[20$ reported that increasing $f$ did not consistently give rise to corresponding increases in heat transfer; the authors [20] identified local maxima in heat transfer, termed critical points, as $f$ increases. They speculated that non-linear flow phenomena between the mist jet, water droplets and surface liquid flow may be responsible, though no local analysis was reported on the influence of $f$ on the liquid film.

75 Graham and Ramadhyani [21] also failed to identify consistent trends in heat transfer with $f$, attributing this to competing heat transfer influences; higher liquid flow rates were thought to lead to thicker surface films, which led to a 
Table 1: Mist jet flow rates examined within the literature and in this study

\begin{tabular}{|c|c|c|c|c|}
\hline Author & $\begin{array}{c}\text { Water flow } \\
\text { rate } \\
Q w[\mathrm{ml} / \mathrm{min}]\end{array}$ & $\begin{array}{c}\text { Water mass } \\
\text { flow rate } \\
\dot{m}_{w}[\mathrm{~kg} / \mathrm{s}] \\
\end{array}$ & $\begin{array}{c}\text { Air mass } \\
\text { flow rate } \\
\dot{m}_{a}[\mathrm{~kg} / \mathrm{s}] \\
\end{array}$ & $\begin{array}{c}\text { Mist loading } \\
\text { fraction } \\
f \\
\end{array}$ \\
\hline Graham and Ramadhyani 21] & $\begin{array}{c}2.4 \\
\text { to } \\
6.9\end{array}$ & $\begin{array}{c}4 \times 10^{-5} \\
\text { to } \\
1.15 \times 10^{-4}\end{array}$ & $\begin{array}{c}2 \times 10^{-4} \\
\text { to } \\
3.1 \times 10^{-4}\end{array}$ & $\begin{array}{c}0.17 \\
\text { to } \\
0.48\end{array}$ \\
\hline Oliphant et al. 25] & $\begin{array}{c}800 \\
\text { to } \\
1800\end{array}$ & $\begin{array}{c}0.013 \\
\text { to } \\
0.03\end{array}$ & $\mathrm{~N} / \mathrm{A}$ & $\mathrm{N} / \mathrm{A}$ \\
\hline Chang and $\mathrm{Su} 20 \|$ & $\begin{array}{l}1330 \\
\text { to } \\
4880\end{array}$ & $\begin{array}{c}0.0222 \\
\text { to } \\
0.0813\end{array}$ & $\begin{array}{c}0.0025 \\
\text { to } \\
0.0058\end{array}$ & $\begin{array}{l}3.8 \\
\text { to } \\
33\end{array}$ \\
\hline Tay et al. 26] & $\begin{array}{c}1.998 \\
\text { and } \\
3.798\end{array}$ & $\begin{array}{c}3.33 \times 10^{-5} \\
\text { and } \\
6.33 \times 10^{-5}\end{array}$ & $\begin{array}{l}2.8 \times 10^{-4} \\
3.8 \times 10^{-4} \\
4.1 \times 10^{-4}\end{array}$ & $\begin{array}{l}0.08 \\
\text { to } \\
0.15\end{array}$ \\
\hline Current study & $\begin{array}{c}0.035 \\
\text { to } \\
0.281\end{array}$ & $\begin{array}{c}5.8 \times 10^{-7} \\
\text { to } \\
4.7 \times 10^{-6}\end{array}$ & $1.97 \times 10^{-4}$ & $\begin{array}{l}0.0030 \\
\text { to } \\
0.0240\end{array}$ \\
\hline
\end{tabular}

decrease in evaporation from the film and a reduction in convective heat transfer from the film to the impinging air flow as the conductive resistance of the film was increased. However, the thickening of the film also means that convective heat transfer to the film flowing along the surface could increase, as its momentum increases with an increase in the liquid flow rate.

Table 1 shows the flow rates that have been considered to date within the literature, as well as the range examined here. To date, only a small range has been reported and the results obtained from different studies, where comparable, lack consistency. No results have been reported for mist loading fractions less than $f<0.08$. This aspect of mist jet heat transfer is completely underrepresented in the literature and is of interest as the behaviour of the liquid film is potentially different in this dilute regime. Thus, Graham and Ramadhyani 21 identified that for very small flow rates the film may not be uniform across the surface. This would represent a very different heat transfer situation from that which has been reported to date, with different dominant heat transfer mechanisms expected. 


\subsubsection{Effect of nozzle-to-surface distance}

For impinging mist jet heat transfer there is little information on the effect of nozzle-to-surface distance available. Chang and $\mathrm{Su}[20$, were unable to determine clear trends in heat transfer with $H / D$, with local maxima emerging. Again, the authors 20] speculated that competing heat transfer phenomena and non-linear phenomena may be at play, though no local surface analysis was carried out. data of this nature were reported.

It is clear that there is a lack of understanding on the effect of mist loading fraction on the heat transfer mechanisms of impinging mist jets. The possibility of achieving significant heat transfer enhancement using very small water flow and environmental benefits if the level of understanding was such that optimisation could be achieved. It is also evident that there is no clear understanding of the effect of such parameters as nozzle-to-surface distance and air flow Reynolds 
number for different liquid flow rates. It has been demonstrated that these are complex issues [20] that merit further work, particularly for the case when the air mass flow rate is larger than the liquid flow rate.

One of the main objectives of this study is to address this paucity of information in an attempt to develop a more comprehensive understanding of the mist jet behaviour, in particular for low liquid flow rates. This will be achieved by examining both the time-averaged and fluctuating heat transfer components of the mist jet. Furthermore, no attempt has been made to date to examine the local behaviour of the liquid film that forms on the surface under an impinging mist jet. Most studies have assumed laminar flow of a continuous film but for the very dilute mist jet considered here, the film produced may not exhibit this behaviour. Indeed, for a mist/steam flow Pakhomov and Terekhov [18] highlighted the importance of surface disturbance from droplet impacts on mist/steam heat transfer. Thus, this study attempts to combine local analysis of the surface film behaviour with simultaneous high-speed heat transfer measurements, with a view to elucidating the convective heat transfer mechanisms in dilute impinging mist jets.

\section{Experimental approach}

\subsection{Heat transfer measurements}

The mist jet in this study is generated using a Spraying Systems B1/4 VMAU-316 SS nozzle, and consists of an annular air jet wrapped around an inner water jet. Figure 1 (a) shows an image of the nozzle while figure 1 (b) is a cross-sectional schematic of the nozzle exit. Here, $D$ and $D_{i}$ refer to the outer and inner annular air jet diameters respectively, and $D_{w}$ is the water jet internal diameter; all relevant dimensions are shown on figure 1 (b) The use of an annular air jet affects the choice of characteristic length scales when considering parameters such as jet Reynolds number and the dimensionless nozzleto-surface, $H / D$, and radial, $r / D$, spacings. In this work, the outer diameter is used for the dimensionless spacings, to best represent the spread of the annular 
jet; this is consistent with annular jet studies within the literature, such as that of Ichimiya [27. Typically the Reynolds number, Re, for an annular air jet is defined using the hydraulic diameter, i.e. the difference between the external and internal diameter, $D_{h}=D-D_{i}$, as the length scale [27, 28].

$$
\operatorname{Re}=\frac{U D_{h}}{\nu}
$$

In this expression $U$ is the jet velocity at the nozzle exit and $\nu$ refers to the kinematic viscosity of the jet fluid. For a mist jet, the droplets are carried by the air jet phase [20]; as such the air properties are used to define the Reynolds number for the mist jet in this study.

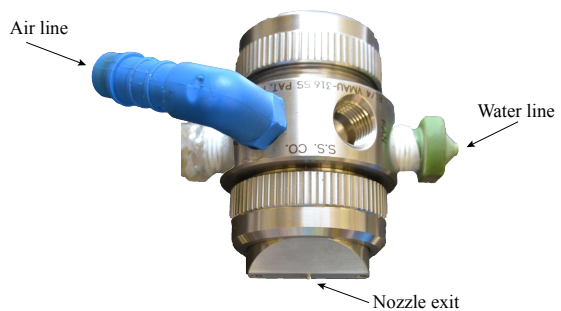

(a)

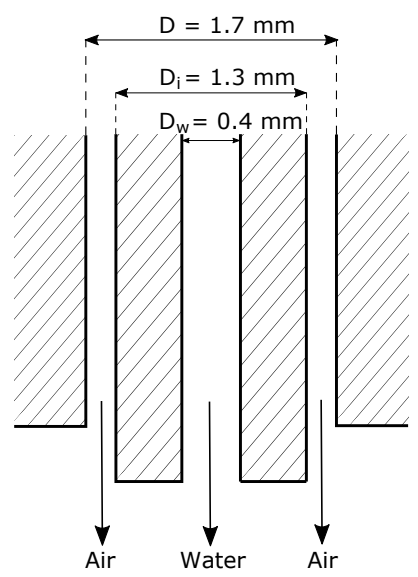

(b)

Figure 1: (a) Spraying Systems B1/4 VMAU-316 SS mist jet nozzle and (b) cross-sectional schematic of mist jet nozzle to scale.

The air flow for the mist jet is regulated using a flow control needle valve connected to a buffer vessel, fed off the laboratory compressed air grid. The flow rate is measured using an Alicat Scientific M-500SLPM-D air flow meter which has an accuracy of $\pm 1 \%$ over a range of $0-500$ SLPM. As well as air flow rates, the uncertainty in Reynolds number depends on the uncertainties in the measurement of the hydraulic diameter and fluid properties. Thus, by propagating the different uncertainties as per Coleman and Steele [29], the uncertainty in 
the standard volumetric flow rate measured by the flow meter was calculated to facturers, and dimensions of approximately $4 \times 2 \mathrm{~mm}$. The total Micro-Foil ${ }^{\circledR}$ area is $6 \times 18 \mathrm{~mm}$. A schematic of the sensor is shown in figure 3 (a). Five thermocouple junction pairs are used within the sensor thermopile to improve 
signal magnitude and resolution and its voltage signal is amplified by a factor of 1000 to improve signal to noise ratio; details on its operating principles are given by Holmberg and Womeldorf [30].

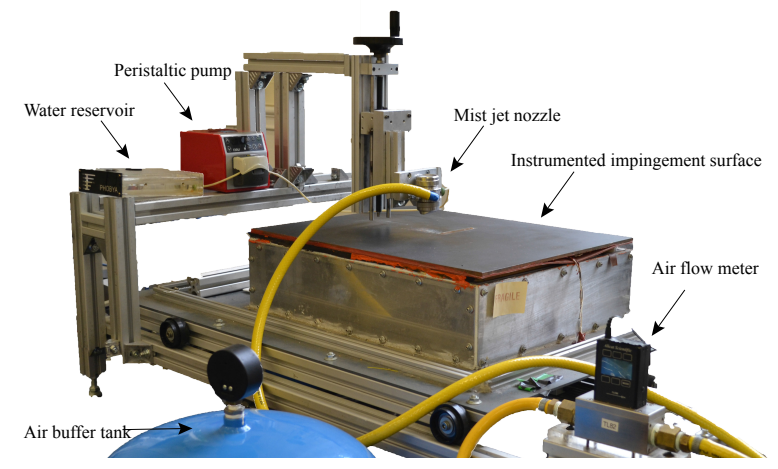

(a)

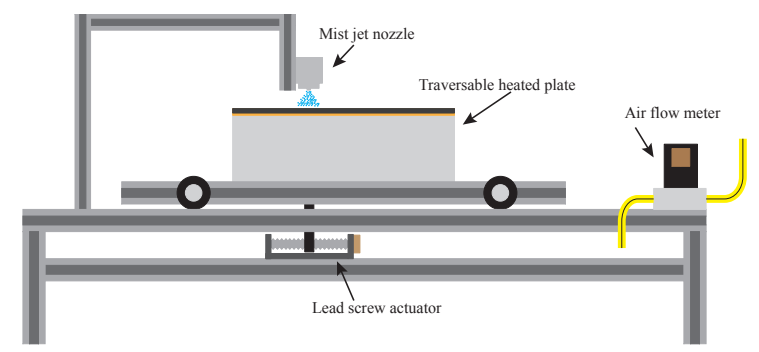

(b)

Figure 2: (a) Photograph and (b) schematic of the heat transfer measurement set-up

Time-averaged heat transfer data are presented in terms of the heat transfer coefficient, $h$. This is consistent with mist jet studies available within the literature, such as Chang and $\mathrm{Su}$ [20] or Tay et al. [31], and also the approach taken in preliminary work by the authors 32 . Heat transfer coefficients are calculated using the expression

$$
h=\frac{q^{\prime \prime}}{T_{s}-T_{j}}
$$

where $T_{s}$ is the surface temperature as measured by the thermocouple embedded within the thermopile heat flux sensor, $T_{j}$ is the jet air temperature, measured 
The adiabatic surface temperature is often used as the reference temperature for complicated flows, as per Li et al. 33. For mist jets, there exists the further issue of which reference fluid temperature to use: the water temperature, as in Fabbri et al. [10] or the air temperature as per Tay et al. [26]. Thermocouples placed and for very small liquid flow rates considered in this investigation the water temperature will have a negligible influence on the overall temperature. Hence the choice of the air temperature as the reference.

A second impingement surface was used to obtain the high-speed fluctuatshown in figure $3(\mathrm{~b})$ Copper leads are also deposited on the polyimide film to act as terminals to connect wires to the CTA module. A Dantec Dynamics 90C10 CTA Module housed in a StreamLine 90N10 Frame is used to set and maintain the temperature of the nickel element to a slight overheat, typically 215 changing its resistance allows for it to be set to a specific temperature. The hot film sensor operating principles are described in detail in O'Donovan et al. 34.

The heat flux from the film is proportional to the voltage applied to the hot film sensor, $E$, to maintain the overheat under a forced convection condition as 


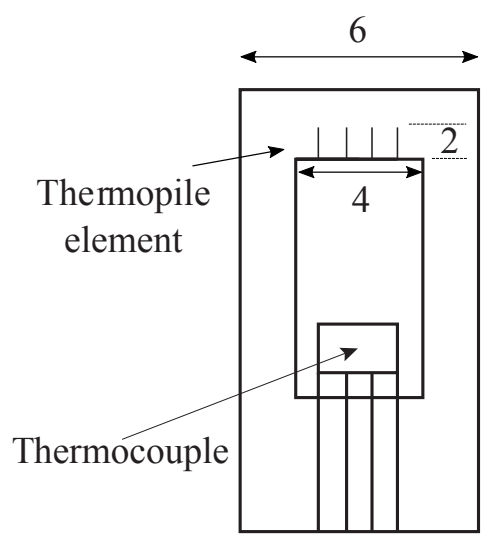

(a)

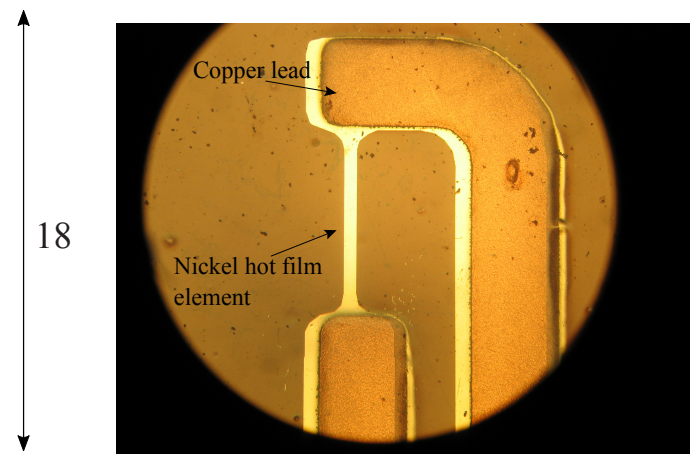

(b)

Figure 3: (a) Schematic of a Micro-Foil ${ }^{\circledR}$ heat flux sensor (dimensions in millimetres) and (b) a magnified view of the Senflex ${ }^{\circledR}$ hot film sensor; the nickel hot film element is $1.4 \mathrm{~mm}$ long and $0.1 \mathrm{~mm}$ wide.

per equation 4

$$
q^{\prime \prime} \propto \frac{E^{2}}{R}
$$

where $R$ is the resistance of the hot film sensor. In the current study, the fluctuations in the normalised mist jet heat flux, $q_{n o r m}^{\prime \prime}$, are used as an indication of the temporal variations in heat flux. The mist jet heat flux is normalised by the air jet heat flux, and is defined as

$$
q_{\text {norm }}^{\prime \prime}=\frac{q_{\text {mistjet }}^{\prime \prime}}{q_{\text {airjet }}^{\prime \prime}}
$$

where $q_{m i s t j e t}^{\prime \prime}$ and $q_{a i r j e t}^{\prime \prime}$ are the mist jet and air jet heat flux measurements respectively.

\subsection{Shadowgraph and high-speed imaging set-up}

Shadowgraph imaging is a particle visualisation technique whereby a uniform light source is placed behind the particles of interest, in this case the mist jet water droplets, while a high-speed camera is focussed on the droplets with the uniform light source in the background. The particles show up as shadows in the images taken of the flow, and their size, position and velocity can 
be inferred if a double-pulsed light source is used. Shadowgraph imaging is able to measure directly flow information such as spray morphology and the behaviour of the liquid on the impingement surface as the technique uses highspeed greyscale images as opposed to the phase shift information used in phase Doppler anemometry (PDA). Thus it is possible to use the shadowgraph images to perform direct high-speed imaging analysis of features of interest associated with the mist jet, such as the impingement behaviour, as is the case in this investigation.

Berg et al. 35] compared different particle imaging techniques and reported that, although shadowgraphy was not proficient at detecting particles smaller than $5 \mu \mathrm{m}$, it provided results that matched well with other imaging techniques for particles larger than $10 \mu \mathrm{m}$, although the lower limit on particle size depends on the camera and light source used; with the detection set-up described below, the lower limit for detectable droplet size in this study is $15 \mu \mathrm{m}$. Also, unlike other techniques, shadowgraphy does not have an upper limit on the size of droplets that can be detected.

The shadowgraphy technique has become more established in recent years. Pavlova et al. 36, 37, used it in their studies on the controllability of a spray by means of a synthetic jet. Zhang et al. 38 characterised a spray in a non245 boiling heat transfer study with the help of shadowgraph images, while Castanet et al. 39] used this technique to examine secondary droplets produced by drop impact on a heated surface. It has also been used to characterise droplet properties in dense diesel sprays by Blaisot and Yon [40, while Klinner and Willert [4] even presented early work into using the shadowgraph imaging process to reconstruct a 3D distribution of spray droplet sizes.

The procedure used in this investigation is similar to that of Berg et al. 35] and uses a DaVis shadowgraph imaging set-up. A double-pulse high-speed Quantronix Darwin-Duo Nd:YLF laser is used to fluoresce Rhodamine 6G dye dissolved in ethanol contained within a high-speed diffuser; the set-up used is shown schematically in figure 4. The laser light causes the dye to fluoresce mono-chromatically, providing the required uniform background illumination. 
A Photron Fastcam SA1 CMOS camera with $1024 \times 1024$ pixel resolution is used to obtain the shadowgraph images; it is triggered at the same time as the laser light pulses to record two frames with a separation of $5 \mu$ s at a frequency of $1000 \mathrm{~Hz}$. Over 2500 pairs of images are taken per test to provide a sufficiently large sample size of detected droplets. Extension tubes are used between a $105 \mathrm{~mm}$ focal length lens and the high-speed camera, acting as a long-distance microscope with a magnification factor of $3: 1$ and a resolution of $4.9 \mu \mathrm{m}$ per pixel; the field of view is approximately $5 \times 5 \mathrm{~mm}^{2}$ and the depth of focus is approximately $0.7 \mathrm{~mm}$.

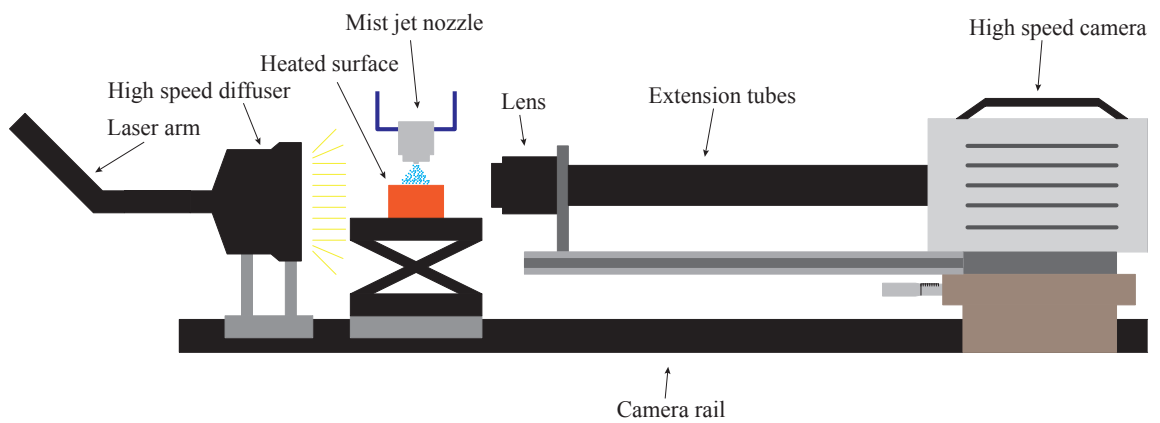

Figure 4: Schematic of the simultaneous shadowgraphy and heat transfer rig

\subsection{Synchronisation of the heat flux and shadowgraph measurements}

Simultaneous high-speed shadowgraphy and hot film sensor measurements are performed using a TTL (Transistor-Transistor Logic) signal, generated using National Instruments LabVIEW ${ }^{\mathrm{TM}}$ software from the computer used to measure the heat transfer signal from the hot film sensor. A cross-correlation is performed between the temporal normalised mist heat flux signal and the detection of droplets in the shadowgraph imaging frames. This allows the two systems to be recombined, which is done by shifting the heat flux signal by the lag identified by the cross-correlation of the signals. 


\subsection{Uncertainty analysis}

The uncertainty associated with the time-averaged heat transfer coefficient consists of its measurement uncertainties, $U_{h}$, and also the uncertainties associated with the mist jet air and water flow rates, $U_{m i s t}$. The uncertainty analysis was performed as per Bendat and Piersol [42] and Mills and Chang 43. For the heat transfer coefficient, the primary uncertainty components were the heat flux signal and the temperature measurements. The total uncertainty in the heat transfer coefficient, $\Delta h$ is given by

$$
\Delta h=\sqrt{U_{h}^{2}+U_{m i s t}^{2}}
$$

The uncertainty associated with the measurement of time-averaged heat transfer coefficients across the range of parameters investigated was calculated to be \pm 8.5 $\%$. Combining this with the uncertainties in the air and water flow rates gives a total uncertainty in the time-averaged heat transfer coefficient of $\pm 10 \%$. The total uncertainty in the time-varying signal obtained using the hot film sensor was calculated to be $\pm 8.6 \%$.

As shadowgraphy is a direct imaging technique, uncertainty analysis tends to focus on comparing images of an object of a known size with physical measurements of the object's size [38, 44, as per the method of setting the micron per pixel resolution. Thus, the uncertainty in the shadowgraph measurements depend on the uncertainty in the size of the known object and the uncertainty associated with setting the scale, i.e. choosing the correct pixel locations corresponding to the edges of the object. The calculated uncertainty therefore was $2.16 \%$. This value is comparable to previous work using shadowgraphy by Zhang et al. 38, who used standard particles, GBW(E)120007 to calibrate their system. Pavlova et al. 37] used the same method to calculate their uncertainty and also reported a similar value.

A more detailed discussion of the uncertainties associated with this investigation is given in Quinn [45]. 


\section{Results and discussion}

\subsection{Time-averaged heat transfer results}

Time-averaged heat transfer coefficient profiles are shown in figures 5 (a) and 5 (b) for a jet Reynolds number of 4500 and a representative sample of mist loading fractions at nozzle-to-plate spacings of $H / D=5$ and $H / D=10$ respectively. Also shown are the equivalent profiles for the annular air-only jet, i.e. $f=0$. It can be seen that the heat transfer profile for the mist jet has the same bell-shaped distribution as observed for round air jets [4, and for the annular air jet, with a peak at the jet centreline, $r / D=0$. Similar bell-shaped profiles are seen in the work of Chang and $\mathrm{Su}$ [20, and the heat transfer distributions here are broadly consistent with the work of Graham and Ramadhyani [21] and Tay et al. 26] for an impinging mist jet without boiling; these authors reported higher heat transfer levels, which is not unexpected as their mist loading fractions are higher than those under investigation here, as is evident from table 1. It is immediately clear that the addition of even very small amounts of liquid to the annular air jet has significantly enhanced the heat transfer coefficient of the jet.

Considering figure $5(\mathrm{a})$, overall the stagnation point heat transfer coefficient is seen to increase with increasing mist loading fraction for this Reynolds number. However, the increase in $h$ is not consistent across the range of $f$. 315 Thus, there is a significant initial increase in stagnation heat transfer coefficient with the introduction of the lowest mist loading fraction of $f=0.0030$; this continues as $f$ increases to 0.0049 and 0.0060. Subsequent to this, the heat transfer coefficient profiles are nearly identical for $f=0.0060, f=0.0085$ and $f=0.0096$, before rising somewhat and broadening significantly for $f=0.0240$.

${ }_{320}$ A similar mid-range plateau is seen for $H / D=10$ in figure 5 (b). The mist jet heat transfer mechanisms proposed by Graham and Ramadhyani 21] and Chang and $\mathrm{Su}$ [20] suggest that increasing the mist loading fraction should lead to an increase in $h$ as it increases the rate of continuous convection to and evaporation from the surface liquid film. However, in both studies inconsistent 


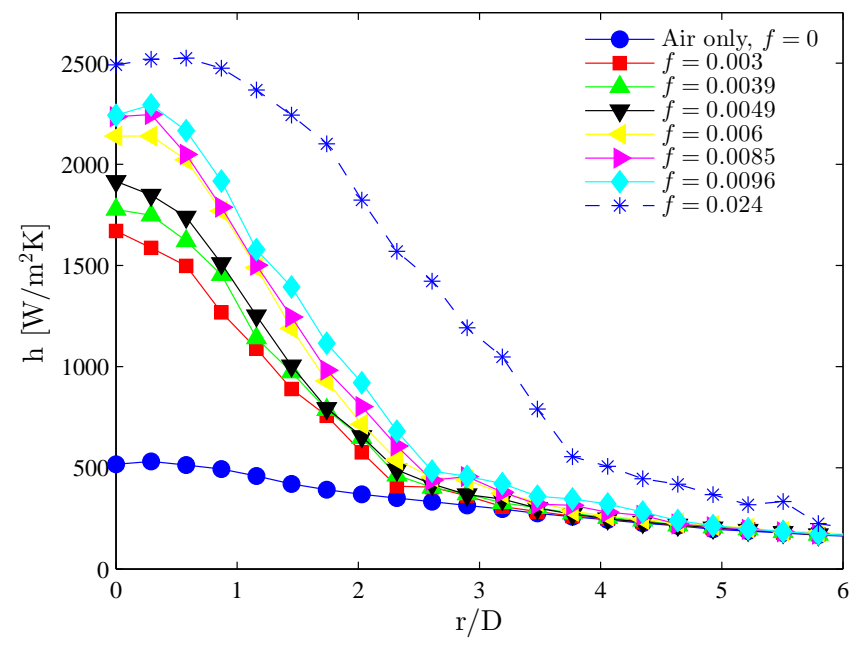

(a) $H / D=5$

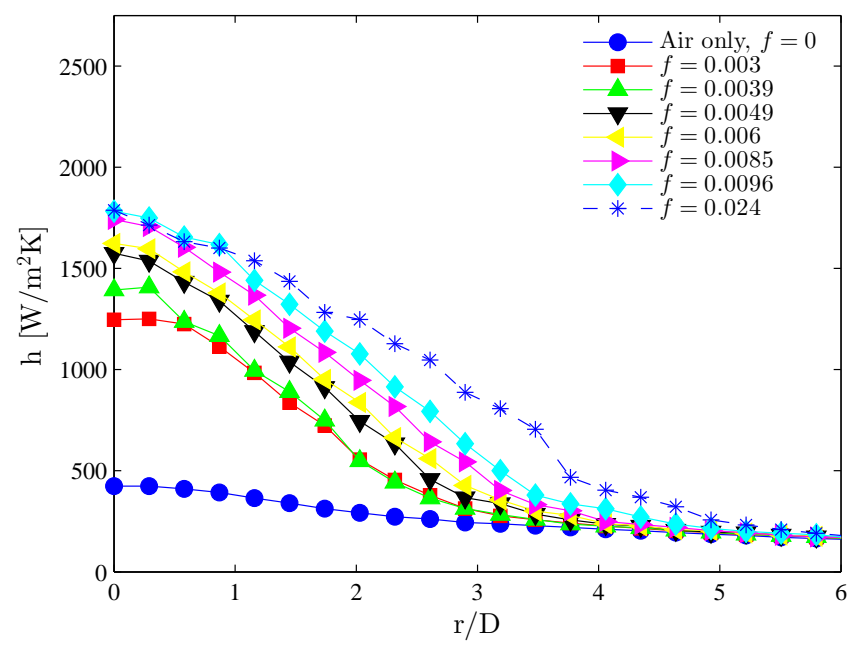

(b) $H / D=10$

Figure 5: Time-averaged heat transfer coefficient profiles for $\mathrm{Re}=4500$ as a function of mist loading fraction, $f$

trends in heat transfer with mist loading fraction were identified.

The heat transfer profiles in figure 5 show some radial variation in heat transfer coefficient with increasing mist loading fraction, particularly for H/D 
$=5$ in figure $5(\mathrm{a})$ The profile for the highest mist loading fraction examined is clearly broader than those for lower $f$. This finding is similar to Chang and $\mathrm{Su}$ 20, who attributed this to the spread of the liquid film increasing with mist loading fraction. As with the stagnation heat transfer coefficient, the radial behaviour is not consistent across the range of mist loading fractions. However, the mist jet profiles for loading fractions less than 0.024 tend to collapse to the same level as the air only profile in similar radial locations; $\mathrm{r} / \mathrm{D} \sim 3$ for $\mathrm{H} / \mathrm{D}=5$ and $\mathrm{r} / \mathrm{D} \sim 4$ for $\mathrm{H} / \mathrm{D}=10$, indicating the edge of the influence of the water component of the mist jet.

For the low mist loading fractions under investigation here, both the stagnation heat transfer coefficients and radial behaviour do not increase consistently with increasing $f$. As such, an examination of the behaviour of the surface liquid may shed light on the heat transfer phenomena at play for dilute mist jets.

\subsection{Characterisation of the surface liquid film and droplet size distribution}

As the surface temperature is below the saturation temperature of the mist jet droplets, liquid will gather on the impingement surface; this is referred to as the liquid film. Studies to date have assumed the presence of a continuous liquid film, and the heat transfer mechanisms proposed have been based on this assumption. However, it has been suggested that at very low liquid flow rates a continuous film may not form [21]; this would imply different heat transfer behaviour than has been reported within the literature for these very low mist loading fractions. Thus, the behaviour of the liquid film is explored here. Images of the surface liquid film were obtained using the same set-up as was used for shadowgraph imaging. Videos of the film behaviour described in this section are available in the on-line version of this paper ${ }^{2}$.

The behaviour of the liquid film for $\mathrm{Re}=4500$ displays similar traits for both nozzle-to-plate spacings considered; analysis of the high-speed imagery allows for the behaviour to be categorised as three regimes for the dilute mist jet under

\footnotetext{
${ }^{2}$ Link to the videos to be included here
} 
investigation: low mist loading fractions $(0.0030<f<0.0060)$, intermediate mist loading fractions $(0.0060<f<0.0130)$ and high mist loading fractions $(0.0130<f<0.0240)$. These regimes are described here.

Some features of the mist jet liquid on the impingement surface in the low mist loading fraction regime can be seen in figures $6(\mathrm{a})$ and $6(\mathrm{~b})$ for $H / D=5$ and $H / D=10$ respectively (for more detail see the videos included in the web version). For both nozzle-to-plate spacings, the liquid on the surface does not form a continuous film. Instead, the low $f$ regime is characterised by small discrete pools of water, referred to here as liquid slugs, with some areas of the surface being dry. These slugs develop close to the jet centreline and grow as droplets impinge on the surface, either due to direct impact from an impinging droplet or by coming in contact with another nearby liquid slug. In general, when coalescence occurs the resulting slug moves outwards from the jet centreline. In this manner, the surface liquid flows outwards from $r / D=0$. Video 1 shows this behaviour more clearly. Here, the discrete liquid slugs can be identified and seen moving outwards under coalescence.

As the mist loading fraction increases within the low $f$ regime, the liquid slugs become more numerous and closely spaced, in particular at the centre of the impingement zone. With further increases in $f$, the behaviour of the liquid on the surface enters what is identified here as the intermediate $f$ regime. Figure 7 shows a sample mist loading fraction that exhibit this intermediate regime behaviour for $H / D=5$ and $f=0.0090$; the surface images for $H / D=10$ show the same features and are not included here. This regime is characterised by the onset and development of a continuous liquid film around $r / D=0$, with the continued presence of liquid slugs away from the centre.

As $f$ increases and more slugs gather on the surface in the central impingement region, the tendency of the discrete liquid slugs to coalesce increases, and the liquid slugs become thinner and elongated, essentially forming localised 385 liquid films. As this happens, the liquid flows outwards in a more continuous fashion than when in slug form under the action of the impinging droplets. This behaviour is seen for both jet-to-plate spacings at the same mist loading frac- 


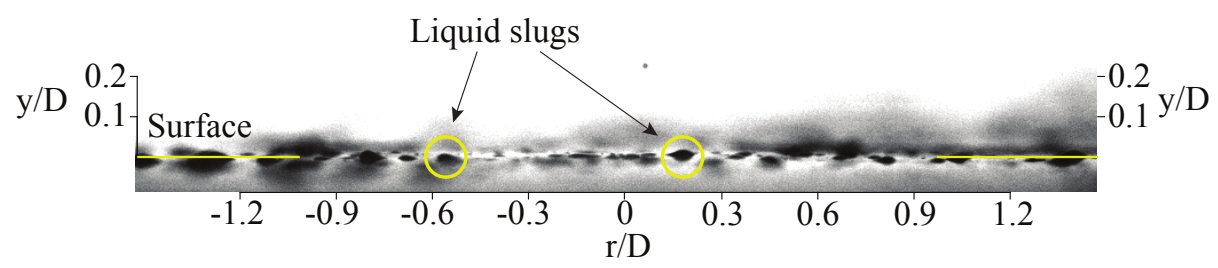

(a)

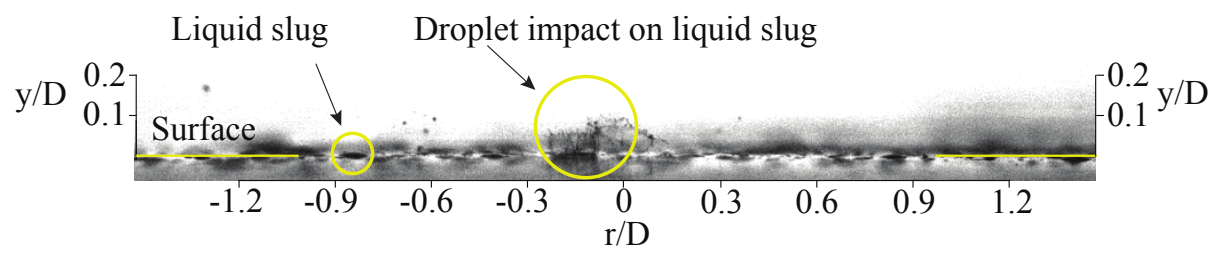

(b)

Figure 6: Liquid film in the low mist loading fraction, $f$, regime for $\operatorname{Re}=4500$ and $f=0.0043$; (a) $H / D=5$ and (b) $H / D=10$

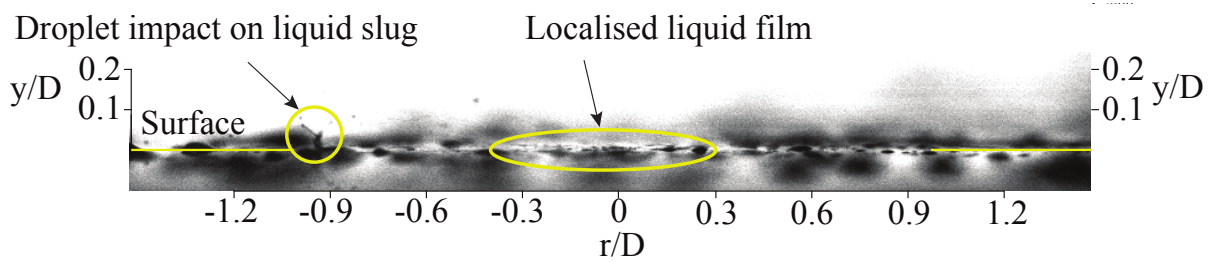

Figure 7: Liquid film in the intermediate mist loading fraction, $f$, regime for $\operatorname{Re}=4500$, $f=0.0090$ and $H / D=5$

tions. As the mist loading increases, these localised films tend to flow together and merge, leading to the development of a continuous liquid film in the centre of the impingement region and the onset of the high $f$ regime. Larger slugs are still evident on the periphery of the impingement region in this regime. Video 2 shows this process in action.

Figure 8 shows an examples of the high mist loading regime for $H / D=5$ when $f=0.0240$; again the images for $H / D=10$ display the same features and are not included here. As the continuous film formed at the centre flows 


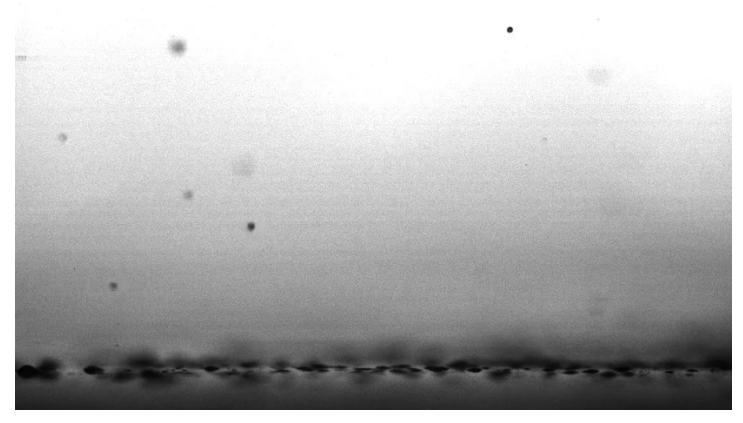

LowMistLoadingFraction.mp4 video goes here

Video 1: Low mist loading fraction liquid film behaviour

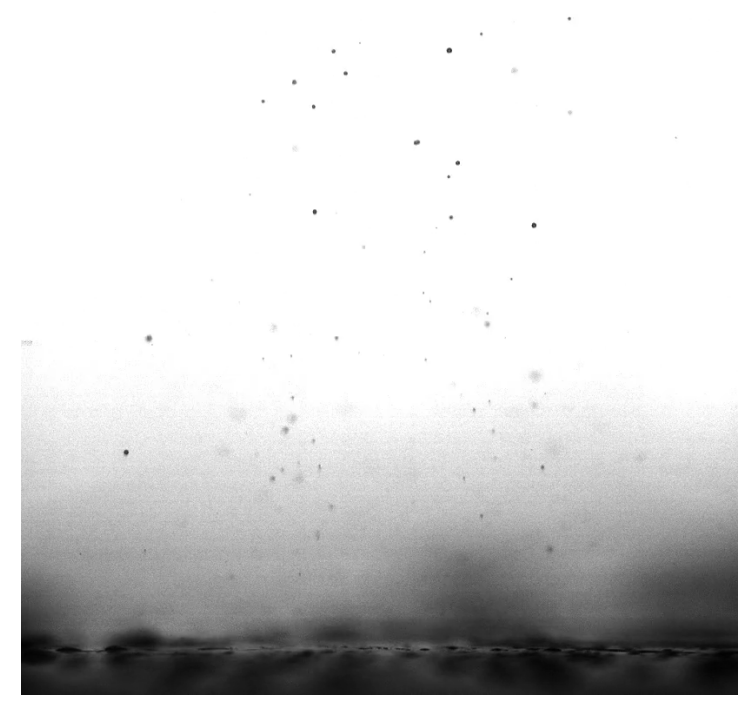

IntermediateMistLoadingFraction.mp4 video goes here

Video 2: Intermediate mist loading fraction liquid film behaviour

outwards under the action of the incoming droplets, the momentum imparted 
from their impacts is eventually dissipated and the film decelerates due to the area increase from radial spreading and the friction between the film and the impingement surface. As this happens, the film tends to revert to liquid slugs, because of surface tension effects. In this regime, splashes in the liquid film can be seen, as identified in figure 8. As the mist loading fraction is increased further, the continuous liquid film spreads over a greater area of the surface, but is otherwise unchanged. However, it must be noted that no quantitative examination of the film thickness was possible with this experimental set-up. Video 3 provides a clearer illustration of this behaviour.

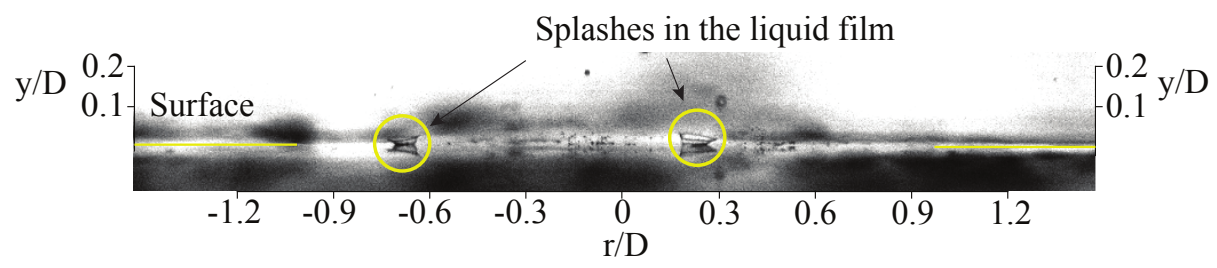

Figure 8: Liquid film in the high mist loading fraction, $f$, regime for $\operatorname{Re}=4500, f=0.0240$ and $H / D=5$

Data obtained on the droplet properties, i.e. size, velocity and number, using the shadowgraph imaging technique sheds some light on the driving mechanism behind the evolution of the surface liquid behaviour. Figure 9 illustrates the measurement zones associated with the two nozzle-to-plate spacings for the shadowgraph imaging undertaken in this study: $2.6<y / D<4$ for $H / D=5$ and $7.6<y / D<9$ for $H / D=10$. Figures $10(\mathrm{a})$ and $10(\mathrm{~b})$ show both the Sauter mean, $\mathrm{D}_{3,2}$, and arithmetic mean, $\mathrm{D}_{1,0}$, diameter in these zones as a function of the mist loading fraction for $H / D=5$ and $H / D=10$ respectively. While there is some scatter in the Sauter mean diameter data, potentially due to a smaller sample size at lower $f$, it is clear that the mean diameter size remains relatively constant across the range of mist loading fractions considered here. For $H / D=10$ in figure $10(\mathrm{~b})$ there does appear to be a slight initial increase in $\mathrm{D}_{1,0}$ with $f$. This could be related to the increasing number of droplets generated as $f$ increases; when $f$ is larger and there is a higher concentration 


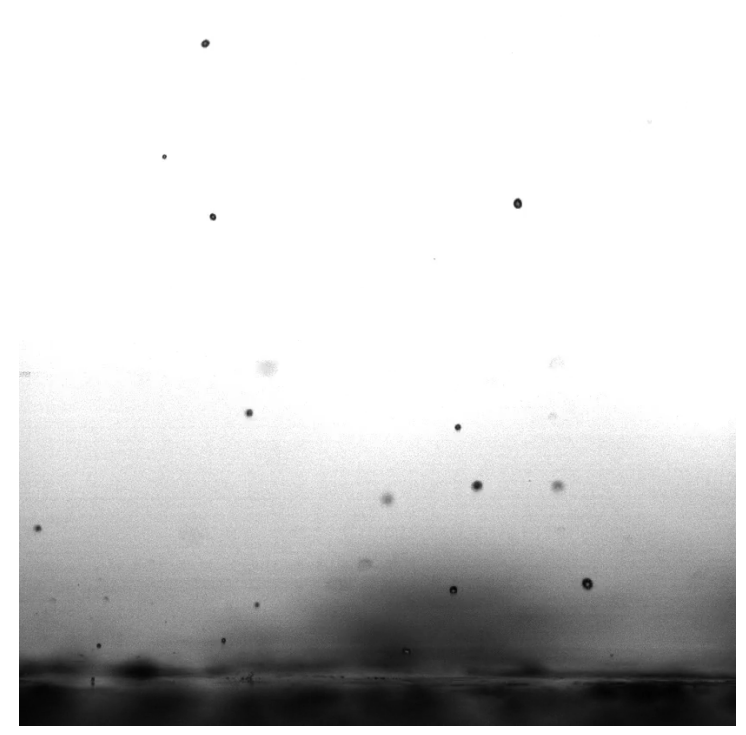

HighMistLoadingFraction.mp4 video goes here

Video 3: High mist loading fraction liquid film behaviour

of droplets, there is a greater chance of bigger droplets surviving downstream, thereby resulting in slightly smaller droplet sizes at the lowest $f$ considered here. Comparing the two $H / D$ cases, the mean diameters have decreased slightly from $H / D=5$ to $H / D=10$ for the same mist loading fractions. This is likely due to the fact that larger droplets continue to undergo atomisation as they move further downstream and are subjected to the air jet for a longer period, termed secondary or far-field atomisation [8], thereby decreasing their size. However this change is small, and the main finding from the droplet size data is the uniformity of the mist jet structure in terms of its droplet size across the range of $f$ examined.

Information on droplet velocities was also obtained using the shadowgraph imaging technique. Figures $11(\mathrm{a})$ and $11(\mathrm{~b})$ show the change in droplet velocity magnitude with increasing downstream distance, $y / D$, for when $H / D=5$ and $H / D=10$ respectively. These data show that the droplets continue to accelerate as they move downstream, as they undergo continued momentum transfer from 435 the co-flowing air jet. What is perhaps of more interest is the fact that there 


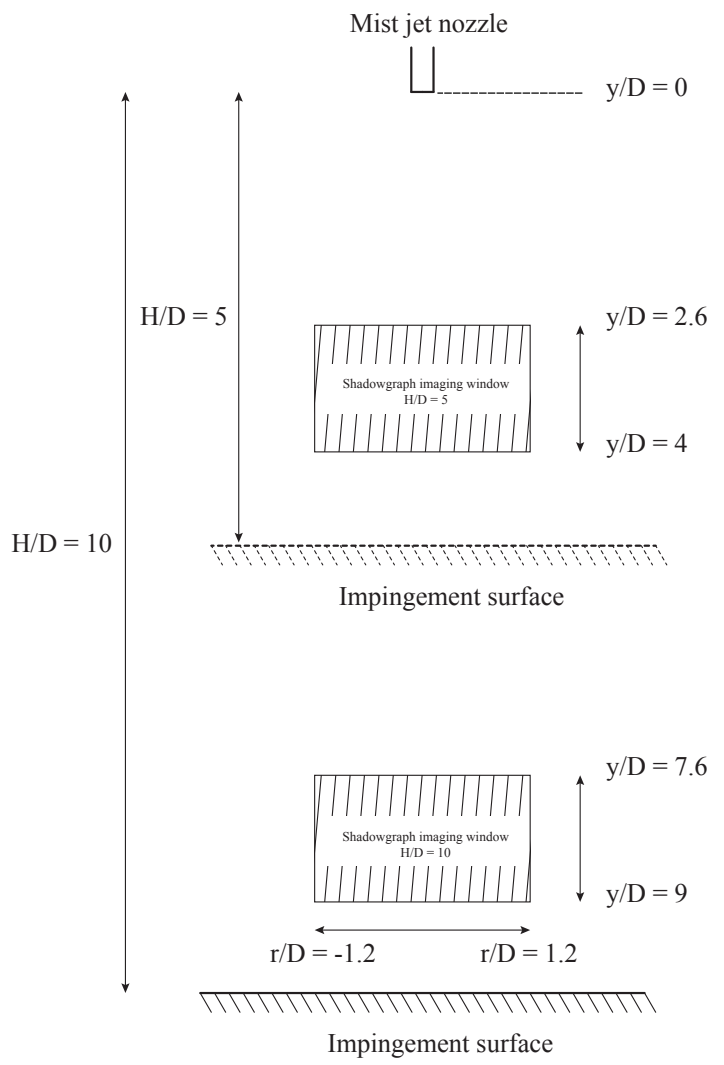

Figure 9: Far-field shadowgraph imaging regions associated with nozzle-to-plate spacings $H / D=5$ (dashed line) and $H / D=10$

is no clear trend in droplet velocity with $f$; as with droplet diameters, droplet velocities do not appear to vary significantly with mist loading fraction, though higher mist loading tends to correspond to slightly lower velocities. This may be due to the increased likelihood of larger droplets surviving downstream as 440 $f$ increases; these droplets do not accelerate as quickly in the air jet due to their larger inertia [8], potentially resulting in the slightly lower velocities here. Figures $12(\mathrm{a})$ and $12(\mathrm{~b})$ show radial distributions of the mean droplet velocity magnitudes as a function of $f$. As well as showing the continued acceleration of the liquid droplets as they move downstream from $H / D=5$ to $H / D=10$, these figures indicate the existence of a central core of higher velocity droplets, 


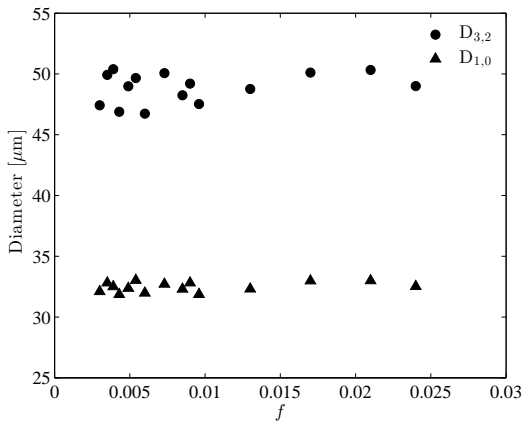

(a)

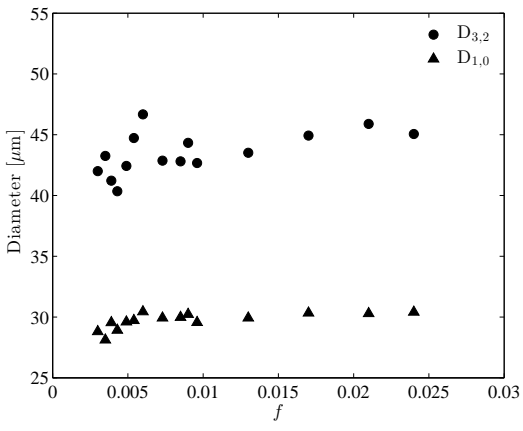

(b)

Figure 10: Sauter mean and arithmetic mean droplet diameters as a function of mist loading fraction at $\operatorname{Re}=4500$; (a) $H / D=5$ and (b) $H / D=10$

with a decrease in velocity as the radial distance from the centreline increases. This behaviour is likely due to the continued acceleration of droplets within the air jet core. The decrease in velocity with increasing $r / D$ may contribute to the forresponding decrease in heat transfer coefficient with $r / D$ seen in figures 5 (a) and 5 (b) However, again there is no clear trend with mist loading fraction Once more, the main trend observed is a near uniformity in the mist jet in terms of velocity for varying $f$.

Considering now the droplet intensity data, a variation in the number of droplets detected with mist loading fraction is clearly evident in figures 13 and 14 , which show the droplet number distributions for $H / D=5$ and $H / D=$ 10 respectively at a representative sample of mist loading fractions. As the mist loading fraction increases, the droplet concentration also increases as more liquid is available for atomisation. The location of the peak number in the droplet size distributions does not vary with increasing $f$, indicating that although the concentration of droplets has increased with $f$, the distribution of droplet sizes does not. This backs up the data on droplet sizes above which indicated little variance in droplet size with mist loading fraction.

It should be pointed out, however, that care must be taken when interpreting the data in figures 13 and 14 . Inherent limitations within the high-speed shad- 


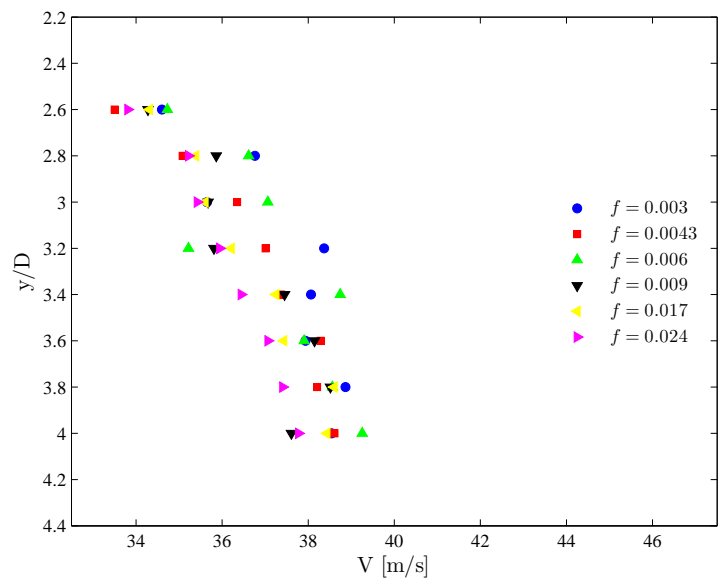

(a)

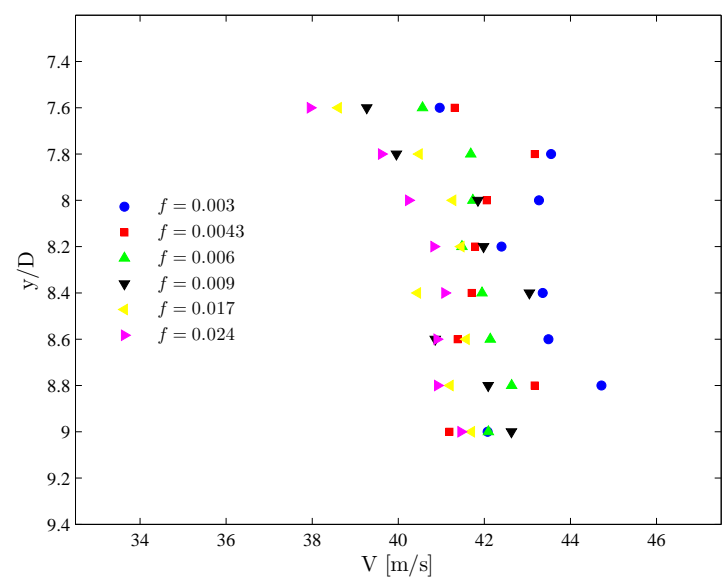

(b)

Figure 11: Mean droplet velocity magnitudes, V, as a function of axial location for a range of mist loading fractions, $f$, when $\operatorname{Re}=4500$; (a) $H / D=5$ and (b) $H / D=10$.

owgraph imaging technique may result in droplets escaping detection. Droplets with a diameter smaller than $15 \mu \mathrm{m}$ cannot be detected by the shadowgraph imaging system used in this study, and droplets that do not pass through the narrow depth of focus of the high-speed camera are not accounted for, as discussed in section 2.2. These constraints may result in the number of droplets measured being smaller than it is in actuality, although the broader trends are 


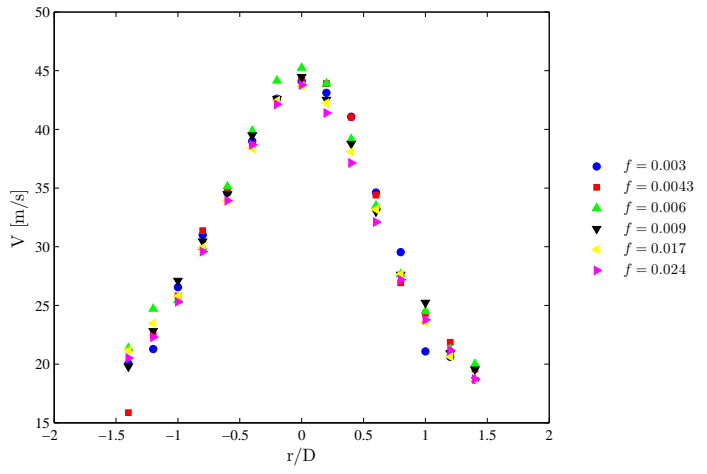

(a)

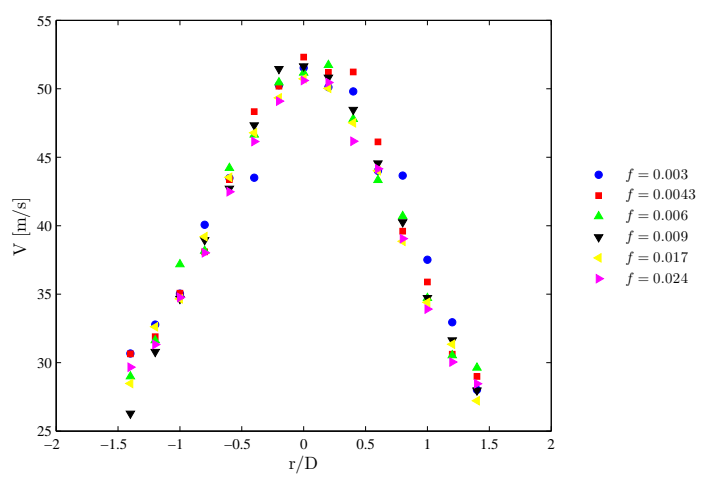

(b)

Figure 12: Radial distributions of mean droplet velocity magnitudes, V, as a function of $f$ when $\operatorname{Re}=4500$; (a) $H / D=5$ and (b) $H / D=10$.

expected to persist.

Taking the droplet property data into account, it seems likely that the driving mechanism that determines the behaviour of the liquid film on the surface is the number of droplets detected, as both the droplet sizes and velocities do not exhibit significant variations with mist loading fraction.

\subsection{Influence of the liquid film on mist jet heat transfer mechanisms}

Turning again to the heat transfer results shown in figure 5 , the initial jump in heat transfer coefficient when water is added to the air jet, and the plateau in the mist jet heat transfer for $f=0.0060, f=0.0085$ and $f=0.0096$ are 


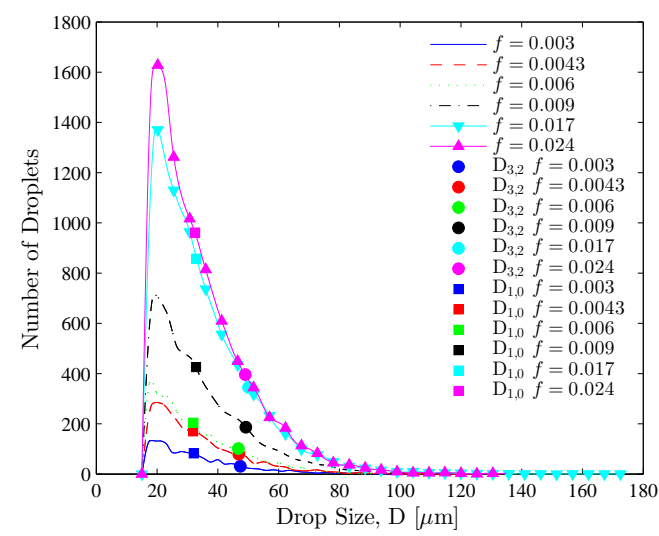

Figure 13: Number distributions of droplet diameter for $H / D=5, \operatorname{Re}=4500$, and a representative sample of $f$

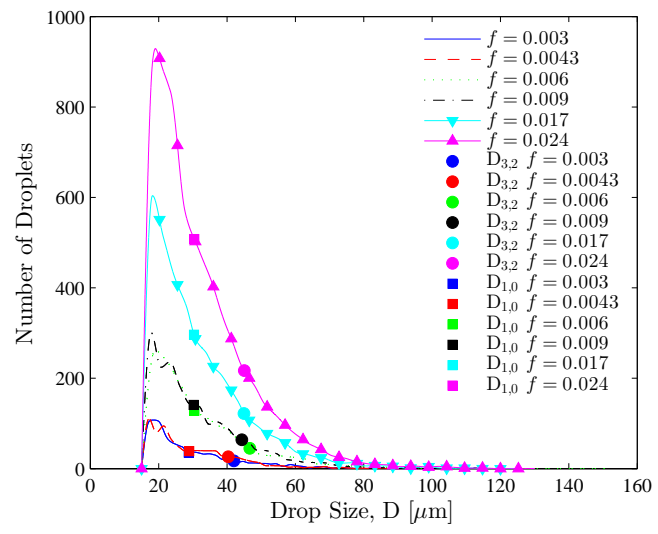

Figure 14: Number distributions of droplet diameter for $H / D=10, \operatorname{Re}=4500$, and a representative sample of $f$

particularly noteworthy when considered in terms of the surface liquid film behaviour. The heat transfer mechanisms reported in the literature [20, 21, 25] rely on the establishment of a continuous liquid film and describe sensible heating of the liquid film, convection to the flowing film and evaporation from the film as the heat transfer mechanisms of significance. However in this study, high-speed imagery has shown that, for low $f$, the discrete liquid slugs that form on the surface are either stationary or move outwards from the stagnation zone in 
a non-continuous fashion, while the localised films associated with intermediate $f$ are intermittent and also not continuous. Thus it is suggested that, while the forced convection of the air jet together with sensible heating and evaporation from the discrete liquid slugs and partial films have some influence, the initial heat transfer enhancement with the addition of liquid droplets is predominately due to disturbance of the surface thermal boundary layer by droplet impacts when the surface is not completely wetted.

The mist loading fractions associated with the plateau in time-averaged heat transfer correspond to the upper-end of the low $f$ surface liquid regime and the transition to the intermediate regime. Thus it appears that after the initial significant jump in heat transfer coefficient when water is added to the air jet, the increase in $h$ slows as $f$ moves through the low surface liquid regime, with little further enhancement for increasing mist loading fraction in the intermediate surface liquid regime. Increasing the mist loading fraction increases the number of discrete slugs in the low $f$ regime, which should enhance the heat transfer through increased evaporation and sensible heating of the slugs. The time-averaged heat transfer coefficient profiles do increase when going from $f=0.0030$ to $f=0.0049$, but the increase is small in comparison to the initial enhancement in heat transfer coefficient, relative to the air only case; this suggests that these contributions to the mist jet heat transfer are small in comparison to the thermal boundary layer disturbances.

The profiles for the mist loading fractions associated with the intermediate surface liquid regime remain broadly similar with increasing $f$; it appears that the formation of a continuous liquid film, and the associated heat removal due to convective flow of the film and evaporation from it, is required to cause further enhancement in heat transfer coefficient. This suggests that the intermediate surface liquid regime may see a transition from a situation where thermal disturbance due to droplet impacts dominate to one where the heat transfer mechanisms associated with the liquid film as described by Graham and Ramadhyani 21, i.e. evaporation and convective flow, dominate.

This transitional behaviour may arise due to competing heat transfer mech- 
anisms. At the lower end of this intermediate range, the surface is less wetted, and hence the droplets can more easily disturb the surface thermal boundary layer; when $f$ is larger, the evaporation and convective flow of the film have been identified as contributing significantly to the mist jet heat transfer. Potentially, for the intermediate range of $f$, the onset of intermittent localised films serves to dampen the influence of the droplet impacts as they are prevented from striking the surface but rather impinge on warmed liquid, while at the same time the rate at which these films flow outwards is not sufficient to significantly enhance the heat transfer through convective action. However, further examination of the surface film beyond the scope of the current measurement set-up is required to affirm this hypothesis.

For the higher $H / D$, it was shown in figure 5 (b) that the increase in stagnation heat transfer coefficient once the liquid film begins to form is not as significant as for $H / D=5$; this may be a consequence of the lower droplet flux at the higher $H / D$ due to the spreading of the jet. The arrival of fresh liquid from the mist jet droplets is what causes the flow of the film, a key component of the mist jet heat transfer, and when there is a lower concentration of droplets the film will flow at a slower rate. Thus, convection from the surface to the film will be reduced and the heat transfer coefficient will not increase to the same extent as when the droplet flux is higher, as in the $H / D=5$ case.

\subsection{Time-resolved heat transfer and droplet dynamics}

Considering the simultaneously obtained time-resolved heat transfer signal and shadowgraph imaging provides evidence for the influence of the droplet impacts on dilute mist jet heat transfer. The normalised mist jet heat flux data from the hot film sensor are for the stagnation region of the mist jet, with the sensor extending over the range of approximately $-0.4<r / D<0.4$ on the surface.

The variations in the normalised mist jet heat flux, $q_{\text {norm }}^{\prime \prime}$, over a period of $2.5 \mathrm{~s}$ for the mist loading fractions of $f=0.0030, f=0.0049$ and $f=0.0060$ at $H / D=5$ are shown in figures $15(\mathrm{a}), 15(\mathrm{~b})$ and $15(\mathrm{c})$ respectively. The first 
two mist loading fractions correspond to the low $f$ surface liquid regime; the latter case represents the transition to the non-continuous localised liquid film behaviour, and the onset of the plateau in time-averaged heat transfer profiles of figure 5 (a) when $H / D=5$ and $\operatorname{Re}=4500$. Also shown in each figure is the $q_{\text {norm }}^{\prime \prime}$ time trace for the air only jet, and the minimum of $q_{n o r m}^{\prime \prime}$ for each mist loading fraction across the measurement period.

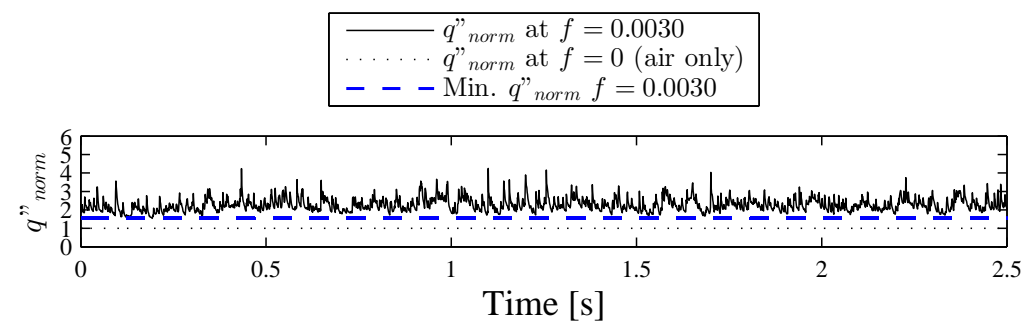

(a)

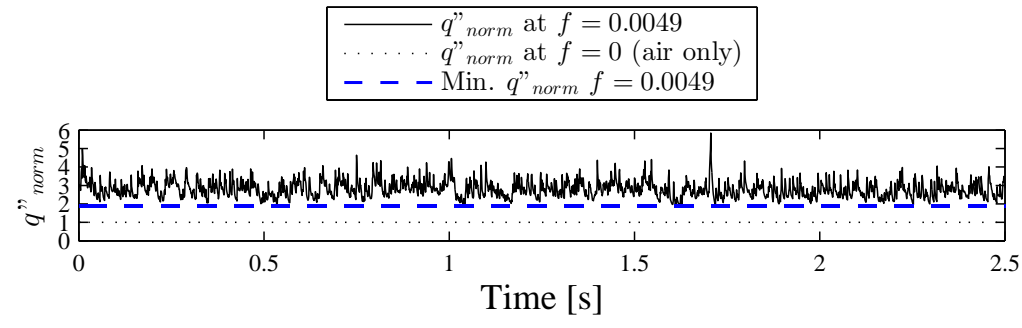

(b)

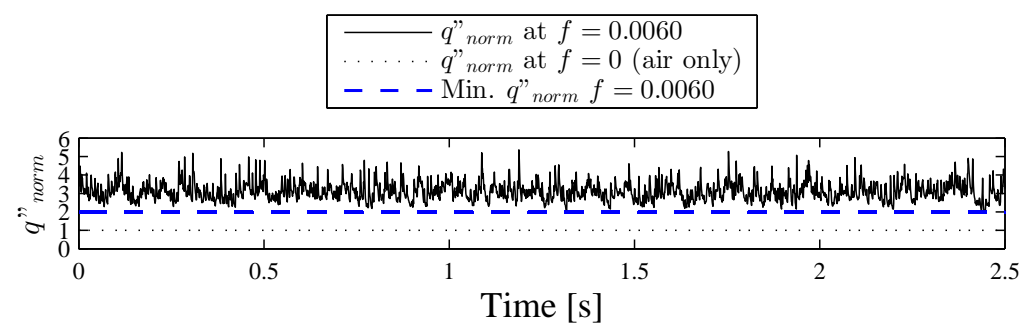

(c)

Figure 15: Temporal variations in normalised mist jet heat flux, $q_{n o r m}^{\prime \prime}$ for $H / D=5$ and $\mathrm{Re}=4500$ at low mist loading fractions of (a) $f=0.0030$, (b) $f=0.0049$ and (c) $f=0.0060$

Immediately apparent is how much more fluctuation there is in the mist jet 

may be indicative of the thermal disruption induced by the addition of the high heat capacity water droplets to the air jet. The trends in time-averaged heat transfer for the same mist loadings are reflected in these temporal distributions of normalised mist jet heat flux. Thus, at the lowest mist loading fraction of jet.

Considering the temporal variations in $q_{\text {norm }}^{\prime \prime}$ along with the simultaneous shadowgraph imagery, the observed spikes in normalised heat flux show a strong dependence on the impingement of droplets on the heated surface. This can be

for $0.5 \mathrm{~s}$, along with the corresponding number of droplets detected per frame. These results are for a mist loading fraction of 0.0060 , which corresponds to the transition between the low and intermediate $f$ surface liquid regimes. Although the fluctuating heat transfer and droplet detection shown in figure 16 show 575 good correspondence, some peaks are evident in the heat flux signal that do not correspond to spikes in the number of droplets detected. While a different heat transfer phenomenon could be responsible, it is more likely that some droplets passing through the detection window in this high-speed flow have been missed due to hardware limitations of the camera. Thus, for a typical droplet the time to pass through the detection window is approximately an order of magnitude shorter than that corresponding to the frame rate of $1000 \mathrm{~Hz}$, which was the maximum frame rate that produced interpretable results.

The evolution of a sample spike in the normalised mist jet heat flux caused by the impinging mist jet, identified by an arrow in figure 16 , provides further 585 elucidation of the observed behaviour. Figures 17, 18 and 19 collectively show 


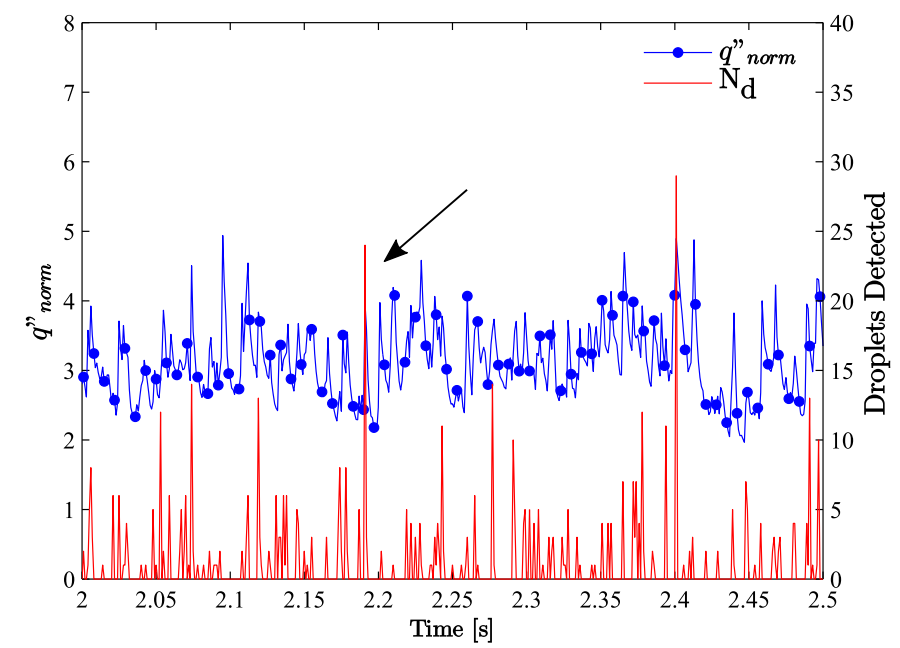

Figure 16: Combined simultaneous normalised mist jet heat flux, $q$ " norm and the number of droplets detected, $\mathrm{N}_{\mathrm{d}}$, for discrete $2-2.5 \mathrm{~s}$ period of figure 15 (c) $H / D=5, \operatorname{Re}=4500$ and $f=0.0060$.

the evolution in $q_{n o r m}^{\prime \prime}$ at a higher temporal resolution, along with the number of droplets detected and the corresponding high-speed shadowgraph images. These images correspond to the region shown in figure 9 extending from $2.6<y / D<4$. Initially for a time period of $t=2.188$ to $t=2.19 \mathrm{~s}$, before the arrival of liquid droplets, $q_{\text {norm }}^{\prime \prime} \approx 2.5$; this is shown in figure 17 . Sensible heating and evaporation of the surface liquid slugs account for this enhancement; this mist loading fraction is on the border between the low and intermediate $f$ regimes. In figure 18, it can be seen that a large number of droplets are now impinging pn the heated surface. This can be seen in the shadowgraph image of figure 18 (b) along with a corresponding peak in the number of detected droplets in figure 18 (a) and a near doubling of $q_{\text {norm }}^{\prime \prime}$. Subsequent to this event, as shown in figure 19, $q_{\text {norm }}^{\prime \prime}$ begins to decay, approaching the level that existed before the impingement of the droplets.

This sequence illustrates the influence of droplet impingement on mist jet 600 heat transfer when the mist loading fraction is so low that a continuous liquid film is not established on the surface. After the initial peak in the normalised 


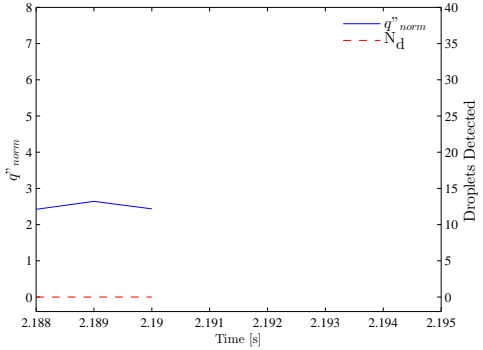

(a)

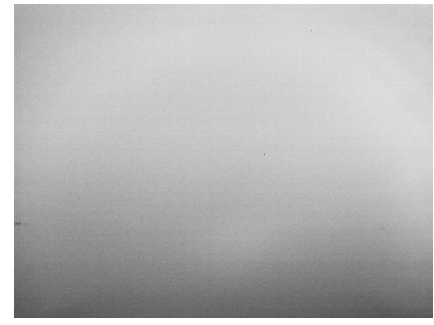

(b)

Figure 17: Before arrival of liquid droplets; (a) normalised mist jet heat flux, $q_{\text {norm }}^{\prime \prime}$, and detected droplets, $\mathrm{N}_{\mathrm{d}}$, and (b) shadowgraph image in the approximate region $2.6<\mathrm{y} / \mathrm{D}<4$. $\operatorname{Re}=4500, f=0.0060$ and $H / D=5$.

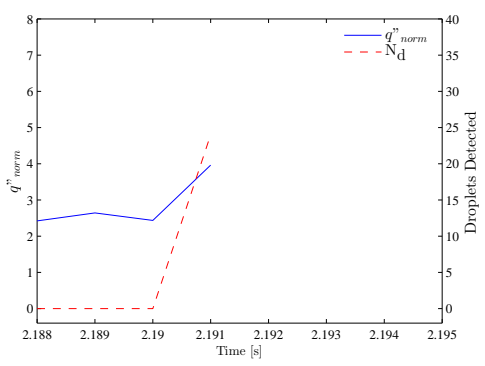

(a)

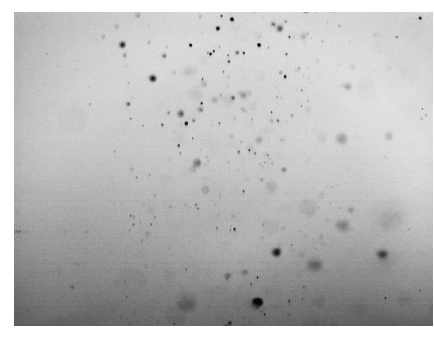

Figure 18: Arrival of liquid droplets; (a) normalised mist jet heat flux, $q_{n o r m}^{\prime \prime}$, and detected droplets, $\mathrm{N}_{\mathrm{d}}$, and (b) shadowgraph image in the approximate region $2.6<\mathrm{y} / \mathrm{D}<4 . \mathrm{Re}=4500$, $f=0.0060$ and $H / D=5$.

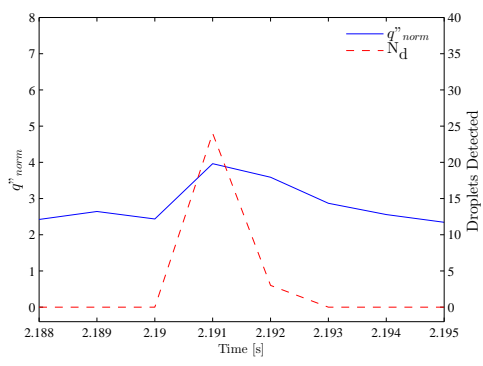

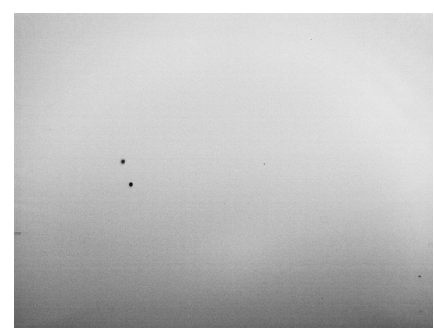

Figure 19: After arrival of liquid droplets; (a) normalised mist jet heat flux, $q_{\text {norm }}^{\prime \prime}$, and detected droplets, $\mathrm{N}_{\mathrm{d}}$, and (b) shadowgraph image in the approximate region $2.6<\mathrm{y} / \mathrm{D}<4$. $\operatorname{Re}=4500, f=0.0060$ and $H / D=5$. 
heat flux, there is a more gradual reduction in $q_{\text {norm }}^{\prime \prime}$ with time; this indicates that the fresh liquid on the surface due to the droplet impingement is removing heat from the surface at a slower rate, likely through sensible heating of the liquid and also due to the outward movement of some liquid slugs. The normalised heat flux will continue to decrease towards a minimum level until a subsequent impingement event causes another spike in $q_{n o r m}^{\prime \prime}$, as seen in figure 16 . The temporal variation in the sensor and droplet detections indicate that while the presence of liquid on the surface does serve to enhance the heat transfer above the air only level, in this low surface liquid regime the disturbance caused by the impingement of the liquid droplets is the main driver for the heat transfer enhancement observed in the time-averaged profiles of figure 5 (a). This behaviour was observed across the range of mist loading fractions that give rise to the discrete liquid slugs.

Figure 20 shows the fluctuating heat transfer signal $\left(q_{\text {norm }}^{\prime \prime}\right)$ for the mist loading fraction of 0.0240 ; which corresponds to the high $f$ surface liquid regime, with a continuous liquid film, as inferred from figure 8. The presence of this film is reflected in the temporal $q_{\text {norm }}^{\prime \prime}$ distribution in figure 20 thus, the minimum instantaneous normalised heat flux for the mist jet is higher here when the continuous film is present than for lower mist loading fractions with intermittent films or discrete liquid slugs. This indicates that, while the droplet impingement still leads to temporal peaks in $q_{\text {norm }}^{\prime \prime}$, the convective flow of the surface liquid film away from the impingement region and evaporation from the film both contribute significantly to heat transfer. Therefore the heat transfer mechanisms for the highest mist loading fraction investigated here are broadly consistent with the findings of Graham and Ramadhyani [21] and others [20, 25].

While further investigation might provide additional elucidation of the heat transfer mechanisms in play as the surface liquid regime evolves from discrete slugs to a continuous film, the current investigation strongly suggests that the disturbances caused by the impingement of the mist jet droplets are the dominant influence on dilute mist jet heat transfer. Thus, the ability of the mist jet to offer significant heat transfer enhancement with the addition of very small 


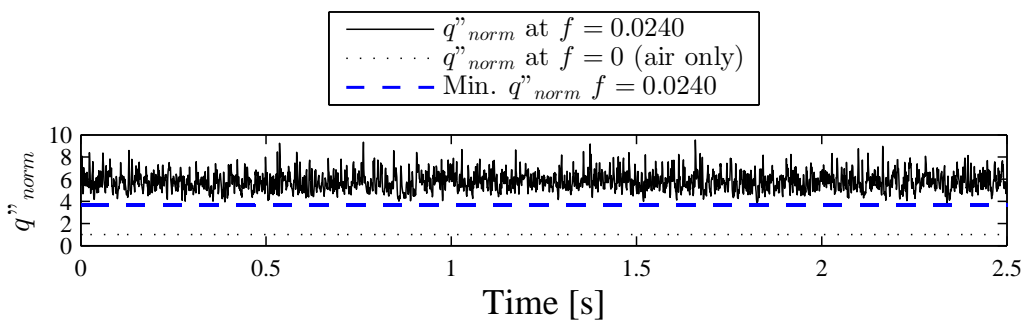

Figure 20: Temporal variations in normalised mist jet heat flux for a mist loading fraction of $f=0.0240$ when $H / D=5$ and $\operatorname{Re}=4500$

amounts of liquid is primarily due to this disturbance to the thermal boundary layer by high heat capacity droplets, rather than to evaporation or heating of a surface liquid film.

\section{Conclusions}

An experimental investigation has been undertake into the heat transfer mechanisms for a dilute impinging mist jet in the non-boiling regime. To this end, time-averaged heat transfer profiles have been examined, along with the mist jet impingement behaviour and flow structure, with simultaneous flow visualisation and heat transfer measurements also being performed. The impingement behaviour of the mist jet was observed to vary with increasing mist loading fraction, $f$. Three regimes were identified to describe the impingement behaviour of the mist jet in terms of mist loading fraction; these can be described as:

1. Low mist loading fraction regime, characterised by discrete liquid slugs forming without complete surface wetting in the impingement region.

2. Intermediate mist loading fraction regime, with the discrete liquid slugs merging to form localised thin liquid films, though still without complete surface wetting.

3. High mist loading fraction regime, where a continuous film of liquid has developed in the impingement region that flows outwards under the action of the impinging droplets. 
Thus, for the low mist fractions under investigation here the surface is not always completely wetted by the impinging mist jet. This is noteworthy as the heat transfer mechanisms proposed in the few studies published on mist jet heat transfer assumed the existence of a continuous liquid film.

Time-averaged heat transfer coefficient profiles were presented for varying mist loading fraction and nozzle-to-plate spacing. Although the heat transfer coefficient increased with mist loading fraction, the increase was not uniform across the range of parameters examined. These time-averaged data pointed towards a link between the surface liquid behaviour and the heat transfer coefficient. Significant high-speed fluctuations in the heat transfer signal were identified which correlated strongly with the detection of droplets in the simultaneous shadowgraph imagery, indicating the importance of thermal disturbances caused by droplet impacts on the impingement surface. As with the liquid film behaviour, the heat transfer mechanisms can be described in terms of increasing mist loading fraction:

1. Low mist loading fraction regime heat transfer enhancement appears to be primarily due to the disturbances caused by the liquid droplets.

2. In the intermediate mist loading fraction regime a plateau in heat transfer coefficient was attributed to competing heat transfer influences as evaporation from and convective cooling by the film became more significant, while the effect of droplet impacts was potentially damped by the developing film.

3. When a continuous liquid film is established, the heat transfer mechanisms are dominated by evaporation and convective flow to the liquid film, resulting in a noticeable heat transfer enhancement.

\section{Acknowledgements} this work, RS/2011/681, under its Postgraduate Scholarship scheme. 


\section{References}

[1] T. S. O'Donovan, D. B. Murray, A. A. Torrance, Jet heat transfer in the vicinity of a rotating grinding wheel, Proc. Inst. Mech. Eng. Part C J. Mech. Eng. Sci. 220 (2006) 837-845.

[2] B. R. Hollworth, M. Durbin, Impingement cooling of electronics, J. Heat Transf. 114 (1992) 607-613.

[3] D. Lytle, B. W. Webb, Air jet impingement heat transfer at low nozzleplate spacings, Int. J. Heat Mass Transf. 31 (1994) 1687-1697.

[4] T. S. O'Donovan, D. B. Murray, Jet impingement heat transfer — part I: mean and root-mean-square heat transfer and velocity distributions, Int. J. Heat Mass Transf. 50 (2007) 3291-3301.

[5] D. T. Vader, F. P. Incropera, R. Viskanta, Local convective heat transfer from a heated surface to an impinging, planar jet of water, Int. J. Heat Mass Transf. 34 (1991) 611-623.

[6] A. Lefebvre, Atomization and sprays, CRC press, 1989.

[7] J. C. Lahseras, E. Villermaux, E. J. Hopfinger, Break-up and atomization of a round water jet by a high-speed annular air jet, J. Fluid Mech. 357 (1998) 351-379.

[8] J. C. Lasheras, E. J. Hopfinger, Liquid jet instability and atomization in a coaxial gas stream, Annu. Rev. Fluid Mech. 32 (2000) 275-308.

[9] J. Kim, Spray cooling heat transfer: the state of the art, Int. J. Heat Fluid Flow 28 (2007) 753-767.

[10] M. Fabbri, S. Jiang, V. K. Dhir, A comparative study of cooling of high power density electronics using sprays and microjets, J. Heat Transf. 127 (2005) 38-48. 
[11] J. R. Rybicki, I. Mudawar, Single-phase and two-phase cooling characteristics of upward-facing and downward-facing sprays, Int. J. Heat Mass Transf. 49 (2006) 5-16.

[12] S. Freund, A. G. Pautsch, T. A. Shedd, S. Kabelac, Local heat transfer coefficients in spray cooling systems measured with temperature oscillation IR thermography, Int. J. Heat Mass Transf. 50 (2007) 1953-1962.

[13] S. S. Hsieh, C. H. Tien, R-134a spray dynamics and impingement cooling in the non-boiling regime, Int. J. Heat Mass Transf. 50 (2007) 502-512.

[14] N. Karwa, S. R. Kale, P. M. V. Subbarao, Experimental study of nonboiling heat transfer from a horizontal surface by water sprays, Exp. Therm. Fluid Sci. 32 (2007) 571-579.

[15] W.-L. Cheng, F.-Y. Han, Q.-N. Liu, H.-L. Fan, Spray characteristics and spray cooling heat transfer in the non-boiling regime, Energy 36 (2011) 3399-3405.

[16] X. Li, J. L. Gaddis, T. Wang, Mist/Steam Heat Transfer in Confined Slot Jet Impingement, Journal of Turbomachinery 123 (2001) 161-167.

[17] X. Li, J. L. Gaddis, T. Wang, Modeling of heat transfer in a mist/steam impinging jet, J. Heat Transf. 123 (2001) 1086-1092.

[18] M. A. Pakhomov, V. I. Terekhov, Second-moment closure simulation of flow and heat transfer in a gas-droplets turbulent impinging jet, International Journal of Thermal Sciences 60 (2012) 1-12.

[19] T. Wang, T. S. Dhanasekaran, Calibration of a computational model to predict mist/steam impinging jets cooling with an application to gas turbine blades, Journal of Heat Transf. 132 (2010) 122201-1-11.

[20] S. W. Chang, L. M. Su, Heat transfer of confined impinging air-water mist jet., JSME Int. J. Ser. B 44 (2001) 274-287. 
[21] K. M. Graham, S. Ramadhyani, Experimental and theoretical studies of mist jet impingement cooling, J. Heat Transf. 118 (1996) 343-349.

[22] M. Garbero, M. Vanni, U. Fritsching, Gas/surface heat transfer in spray deposition processes, Int. J. Heat Fluid Flow 27 (2006) 105-122.

[23] N. Kumari, V. Bahadur, M. Hodes, T. Salamon, P. Kolodner, A. Lyons, S. V. Garimella, Analysis of evaporating mist flow for enhanced convective heat transfer, Int. J. Heat Mass Transf. 53 (2010) 3346-3356.

[24] L. M. Su, S. W. Chang, C. I. Yeh, Y. C. Hsu, Heat transfer of impinging air and liquid nitrogen mist jet onto superheated flat surface, Int. J. Heat Mass Transf. 46 (2003) 4845-4862.

[25] K. Oliphant, B. W. Webb, M. Q. McQuay, An experimental comparison of liquid jet array and spray impingement cooling in the non-boiling regime, Exp. Therm. Fluid Sci. 18 (1998) 1-10.

[26] A. A. O. Tay, S. S. T. Ang, L. O. Lwin, An experimental study of slot-jet impingement and mist cooling of microprocessors, Therm. Thermomechanical Proc. 10th Intersoc. Conf. Phenom. Electron. Syst. 2006. ITHERM 2006. (2006) 175-180.

[27] K. Ichimiya, Heat transfer characteristics of an annular turbulent impinging jet with a confined wall measured by thermosensitive liquid crystal, Heat Mass Transf. 39 (2003) 545-551.

[28] H. Q. Yang, T. Kim, T. J. Lu, K. Ichimiya, Flow structure, wall pressure and heat transfer characteristics of impinging annular jet with/without steady swirling, Int. J. Heat Mass Transf. 53 (2010) 4092-4100.

[29] H. W. Coleman, W. G. Steele, Experimentation, validation, and uncertainty analysis for engineers, 3rd ed., John Wiley \& Sons, 2009.

[30] D. G. Holmberg, C. A. Womeldorf, Performance and modeling of heat flux sensors in different environments, Proc. ASME, Heat Transf. Div. 364 (1999) 71-77. 
[31] Y. Tao, X. Huai, L. Wang, Z. Guo, Experimental characterization of heat transfer in non-boiling spray cooling with two nozzles, Appl. Therm. Eng. 31 (2011) 1790-1797.

[32] C. Quinn, D. B. Murray, T. Persoons, the Effect of Liquid Mass Flow Rate on Heat Transfer for an Air-Water Atomizing Mist Jet, in: 15th International Heat Transfer Conference, IHTC-15, 2014, pp. 1-13.

[33] X. C. Li, J. Zhou, K. Aung, On selection of reference temperature of heat transfer coefficient for complicated flows, Heat Mass Transf. 45 (2008) 633-643.

[34] T. S. O'Donovan, T. Persoons, D. B. Murray, High-resolution hot-film measurement of surface heat flux to an impinging jet, Meas. Sci. Technol. $22(2011)$.

[35] T. Berg, J. Deppe, D. Michaelis, H. Voges, S. Wissel, Comparison of particle size and velocity investigations in sprays carried out by means of different measurement techniques, in: ICLASS-2006, August 27-September 1, Kyoto, 2006.

[36] A. A. Pavlova, K. Otani, M. Amitay, Active performance enhancement of spray cooling, Int. J. Heat Fluid Flow 29 (2008) 985-1000.

[37] A. A. Pavlova, K. Otani, M. Amitay, Active control of sprays using a single synthetic jet actuator, Int. J. Heat Fluid Flow 29 (2008) 131-148.

[38] Z. Zhang, J. Li, P.-X. Jiang, Experimental investigation of spray cooling on flat and enhanced surfaces, Appl. Therm. Eng. 51 (2013) 102-111.

[39] G. Castanet, P. Dunand, O. Caballina, F. Lemoine, High-speed shadow imagery to characterize the size and velocity of the secondary droplets produced by drop impacts onto a heated surface, Exp. Fluids 54 (2013) $1-17$. 
[40] J. B. Blaisot, J. Yon, Droplet size and morphology characterization for dense sprays by image processing: application to the Diesel spray, Exp. Fluids 39 (2005) 977-994.

[41] J. Klinner, C. Willert, Tomographic shadowgraphy for three-dimensional reconstruction of instantaneous spray distributions, Exp. Fluids 53 (2012) $531-543$.

[42] J. S. Bendat, A. G. Piersol, Random data: analysis and measurement procedures, 4th ed., John Wiley \& Sons, 2010.

[43] A. F. Mills, B. H. Chang, Error analysis of experiments, 2007. http:// WWW.seas.ucla.edu/mae/Error_Analysis_of_Experiments.

[44] A. Lecuona, P. A. Sosa, P. A. Rodríguez, R. I. Zequeira, Volumetric characterization of dispersed two-phase flows by digital image analysis, Meas. Sci. Technol. 11 (2000) 1152-1161.

[45] C. Quinn, Heat transfer behaviour of a dilute impinging air-water mist jet, Ph.D. thesis, Trinity College Dublin, 2015. 